\title{
Child Abuse and Deformational Plagiocephaly in a West Texas Hospital System
}

\author{
Preston D’Souza ${ }^{1}$ Keith A. Hanson ${ }^{1}$ Pranati Pillutla ${ }^{1}$ Peyton Presto ${ }^{1}$ Laszlo Nagy ${ }^{2}$ \\ ${ }^{1}$ School of Medicine, Texas Tech University Health Sciences Center, \\ Lubbock, Texas, United States \\ ${ }^{2}$ Department of Pediatrics, Texas Tech University Health Sciences \\ Center, Lubbock, Texas, United States

\begin{abstract}
Address for correspondence Laszlo Nagy, MD, Medical Office Building, 4102 24th Street, Suite 409, Lubbock, TX 79410, United States (e-mail: Laszlo.nagy@ttuhsc.edu).
\end{abstract}

J Neurosci Rural Pract 2020;11:106-112

Abstract

Keywords
- deformational
plagiocephaly
- neglect
- nonaccidental trauma
- pediatric
- rural

Background The aim of this study was to assess deformational plagiocephaly's (DP) predictive value in neglect and physical abuse (nonaccidental trauma [NAT]) within the pediatric population. In addition, we sought to characterize the prevalence of DP and NAT for our hospital's mostly rural catchment area.

Methods Data on hospitalized patients diagnosed with NAT and/or neglect between 2012 and 2018 were collected via retrospective chart review. All enrolled children were younger than the age of 4 years at the time of diagnosis, and those without legible head computed tomographies or magnetic resonance images during their initial hospitalization were excluded. Utilizing neuroimaging, we calculated the cranial vault asymmetry index (CVAI) and cranial index for each patient to assess for DP. Differences between the two groups were assessed using Wilcoxon's rank-sum test for continuous variables and Fisher's exact test for categorical variables. A p-value of 0.05 or less was considered statistically significant. All analyses were conducted using SAS 9.4 (Cary, North Carolina, United States).

Results The prevalence of DP within the combined cohort of NAT and neglect patients is $21 \%$, similar to that reported in the literature for the general population (20-50\%). There was no significance between the prevalence of DP and a history of NAT $(p>0.1)$ or neglect $(p>0.1)$. Furthermore, there was no correlation between CVAI and characteristics of initial presentation or history of trauma for either NAT ( $p$-values: 0.359 and 0.250 , respectively) or neglect groups ( $p$-values: 0.116 and 0.770 , respectively).

Conclusion While there are many limitations to this study, our results suggest that abused children are no more likely to have history of DP than the general population, and the degree of DP is not associated with severity of trauma history or initial presentation. We hope the results of this study promote future investigations for unique and subtle predictive factors of child abuse/neglect.

\section{Introduction}

Nonaccidental trauma (NAT) is one of the main causes of pediatric morbidity and mortality in the United States, and it is estimated that more than 1,000 children die every year from such causes. ${ }^{1}$ Of these deaths, $\sim 80 \%$ are the product of head trauma, and 19 to $38 \%$ of pediatric head trauma cases have been shown to result from physical abuse or neglect. ${ }^{1-3}$ Additionally, pediatric trauma resulting from nonaccidental causes has been shown to have a significantly higher mortality than accidental trauma. ${ }^{2-4}$ The ability to identify potential child abuse victims would prevent significant morbidity and mortality in children.

While some studies have shown associations between child maltreatment and rural residence,,${ }^{4,5}$ age, ${ }^{6}$ sex, ${ }^{7}$ parental mental health, ${ }^{8}$ and family instability, ${ }^{6}$ ultimately, there 
are, as of this writing, no tools for identifying potential abuse victims before the onset of trauma. Currently, even the tools available for diagnosing victimized children are lacking in sensitivity, ${ }^{1,9}$ and most of the current literature focuses on identifying abuse following admission to the hospital. Given the concerns outlined earlier, we hypothesized that deformational plagiocephaly (DP), a malformation of a child's skull that often results from too much time spent lying supine, could act as an early predictor of abuse or neglect. It is a condition that is relatively easy to screen for and the techniques for measurement could easily be applied to rural clinics and emergency room without imaging. However, the current literature is divided on the actual prevalence, incidence, and consequences of DP, which makes comparing our nonaccidental trauma and neglect population to the general population difficult. To help address this inconsistency in the literature, we characterized the occurrence of plagiocephaly and child maltreatment at two west Texas institutions with a large, rural catchment area. We then used these data to evaluate any possible correlation between DP and child maltreatment in our study population.

\section{Methods}

After obtaining Institutional Review Board approval, charts for children younger than the age of 4 years with a diagnosis of NAT (ICD-9: 995.59; ICD-10: T76.12XA), child neglect (ICD-9: 995.52; ICD-10: T76.02XA), and/or unspecified head injury (ICD-9: 959.01; ICD-10: S09.90XA) were collected. Children with developmental delay and torticollis were excluded as these conditions are independent risk factors for DP. ${ }^{10}$ Charts that lacked neuroimaging studies were excluded from analysis. Thus, out of 396 charts that met the inclusion criteria, a total of 76 were used in this study. Demographical information was attained from patients' charts and the evaluation of socioeconomic status (SES) was accomplished using U.S. census data on the median household income for the subject's listed zip code of residence.

Utilizing axial computed tomography (CT) scans, the cranial vault asymmetry index (CVAI) and cranial index (CI) were calculated as described by Loveday and de Chalain ${ }^{11}(-$ Fig. 1). The current model for assessing severity of plagiocephaly was also used. ${ }^{12}$ In this model, a CVAI $<3.5 \%$ indicates normal head symmetry (Level 1), 3.5 to $6.25 \%$ indicates minimal asymmetry (Level 2), 6.25 to $8.75 \%$ indicates moderate to severe posterior quadrant flattening (Level 3), 8.75 to $11.0 \%$ indicates severe posterior quadrant flattening with moderate ear shift (Level 4 ), and $>11.0 \%$ indicates severe posterior quadrant flattening with severe ear shift (Level 5). Therefore, a CVAI > 3.5\% constitutes a diagnosis of DP. Additionally, we assessed the presence of brachycephaly via $\mathrm{Cl}$, with a value above $0.9 \mathrm{~mm}$ being diagnostic for brachycephaly. The calculations for CVAI and CI were performed immediately above ear level on the appropriate CT cut, which allowed us to apply head measurements at the widest diameter of the skull.

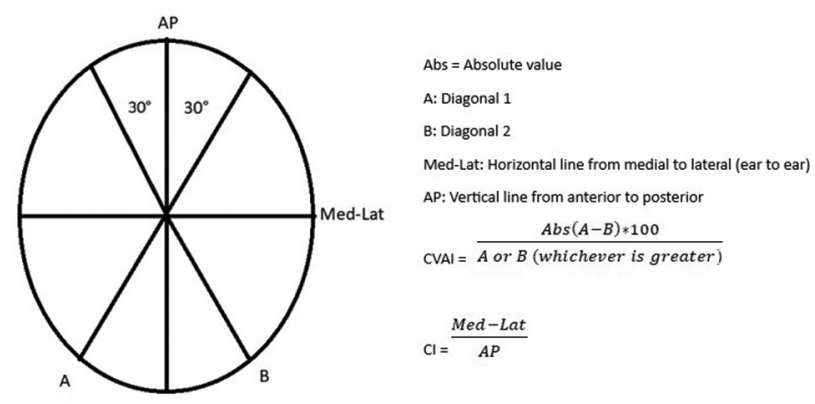

Fig. 1 Model of CT cut and method of calculating CVAl and $\mathrm{Cl} . \mathrm{Cl}$, Cranial Index; CVAI, Cranial Vault Asymmetry Index.

Table 1 Severity of initial clinical presentation

\begin{tabular}{|l|l|}
\hline 0 & No physical trauma \\
\hline 1 & Isolated body soft tissue injury \\
\hline 2 & $\begin{array}{l}\text { Soft tissue injury to head (contusions, lacerations, and } \\
\text { hematoma) }\end{array}$ \\
\hline 3 & $\begin{array}{l}\text { Concussion diagnosis/TBI diagnosis/prolonged } \\
\text { LOC }(>5 \text { s) } \pm \text { soft tissue injuries }\end{array}$ \\
\hline 4 & Extracranial fractures \pm soft tissue injuries \\
\hline 5 & Skull fracture \pm soft tissue injury \\
\hline 6 & $\begin{array}{l}\text { Intracranial pathology (epidural, subdural, and subarach- } \\
\text { noid bleed) + other injuries (extracranial fractures, organ } \\
\text { injury, etc.) }\end{array}$ \\
\hline 7 & $\begin{array}{l}\text { Intracranial pathology (epidural, subdural, and subarach- } \\
\text { noid bleed) + skull fracture }\end{array}$ \\
\hline
\end{tabular}

Abbreviations: $\mathrm{Cl}$, cranial index; $\mathrm{CT}$, computed tomography; CVAl, cranial vault asymmetry index; LOC, loss of consciousness; TBI, traumatic brain injury.

Table 2 Severity of history

\begin{tabular}{|l|l|}
\hline 0 & No trauma of any kind \\
\hline 1 & Direct physical abuse \\
\hline 2 & Neglect-physical \\
\hline 3 & Neglect-supervisory \\
\hline 4 & Direct abuse + neglect (combined) \\
\hline
\end{tabular}

Next, scales were created to assess the characteristics of initial clinical presentation as well as severity of the patient's history (-Tables $\mathbf{1}$ and 2). Neglect history was stratified into "supervisory" and "physical" neglect. ${ }^{13}$ Finally, demographical information was collected for each patient, including age, race, ethnicity, sex, and median household income.

For our analysis, severity of initial presentation, severity of history, and severity of brachycephaly were evaluated in children with and without DP. Also, children with DP in the NAT group were compared with those diagnosed with DP in the neglect group using the same factors. Statistical differences between the groups were assessed using Wilcoxon's rank-sum test for continuous variables and Fisher's exact test for categorical variables. A p-value of 0.05 or less was considered statistically significant. All analyses were conducted using SAS 9.4 (Cary, North Carolina, United States). 


\section{Results}

The prevalence of plagiocephaly within the combined cohort of NAT and neglect patients was $21 \%$ (-Table 3 ). The percentage of NAT patients with DP was $23.68 \%$ and the percentage of neglect patients with DP was $18.4 \%$ (-Tables 4 and 5 ). There was no logistical correlation between CVAI and characteristics of initial presentation or history of trauma for either NAT ( $p=0.359$ and 0.250 , respectively) or neglect patients ( $p=0.116$ and 0.770 , respectively). No significant association was found between brachycephaly and plagiocephaly in either the NAT ( $p=0.148$ ) or neglect $(p=0.425)$ groups. The median age for children in the NAT and neglect group that were diagnosed with plagiocephaly was 3 months (-Table 4) and 12 months (-Table 5), respectively. Finally, no predictive significance was seen between age, ethnicity, race, or SES and a history of NAT or neglect ( - Tables 4 and $\mathbf{5}$ ). All associated $p$-values and information on additional studied variables for each group are shown in-Tables 3 to 5 .

Table 3 Sample characteristics of all patients (NAT and neglect) by plagiocephaly status

\begin{tabular}{|c|c|c|c|c|}
\hline & \multirow[t]{2}{*}{ Overall $(n=76)$} & \multicolumn{2}{|c|}{ Plagiocephaly } & \multirow[t]{2}{*}{$p$-Value } \\
\hline & & No $(n=60)$ & Yes $(n=16)$ & \\
\hline Age, median (IQR) & $14.5(5-24)$ & $18(7-30)$ & $4(3-19)$ & 0.05 \\
\hline Median income, median (IQR) & $50,510(41,383-63,642)$ & $51,335(41,441-63,837)$ & $47,391(39,639-56,361)$ & 0.48 \\
\hline \multicolumn{5}{|l|}{ Age group, $n(\%)$} \\
\hline$\leq 12$ & $37(48.68)$ & $26(43.33)$ & $11(68.75)$ & \multirow{2}{*}{0.07} \\
\hline$>12$ & $39(51.32)$ & $34(56.67)$ & $5(31.25)$ & \\
\hline \multicolumn{5}{|l|}{ Sex, $n(\%)$} \\
\hline Male & $37(48.68)$ & $28(46.67)$ & $9(56.25)$ & \multirow{2}{*}{0.50} \\
\hline Female & $39(51.32)$ & $32(53.33)$ & $7(43.75)$ & \\
\hline \multicolumn{5}{|l|}{ Ethnicity, $n(\%)$} \\
\hline Non-Hispanic & $32(45.71)$ & $26(46.43)$ & $6(42.86)$ & \multirow{2}{*}{0.81} \\
\hline Hispanic & $38(54.29)$ & $30(53.57)$ & $8(57.14)$ & \\
\hline \multicolumn{5}{|l|}{ Race, $n(\%)$} \\
\hline White & $46(60.53)$ & $34(56.67)$ & $12(75)$ & \multirow{3}{*}{0.70} \\
\hline Black & $10(13.16)$ & $9(15)$ & $1(6.25)$ & \\
\hline Other & $11(14.47)$ & $9(15)$ & $2(12.5)$ & \\
\hline \multicolumn{5}{|l|}{ Initial-pre, $n(\%)$} \\
\hline $\begin{array}{l}\text { Neglect only-no direct physical } \\
\text { trauma of any kind }\end{array}$ & $9(11.84)$ & $7(11.67)$ & $2(12.5)$ & \multirow{8}{*}{0.36} \\
\hline No trauma to the head & $10(13.16)$ & $7(11.67)$ & $3(18.75)$ & \\
\hline Soft tissue injury to head & $21(27.63)$ & $18(30)$ & $3(18.75)$ & \\
\hline $\begin{array}{l}\text { Soft tissue injury + concussion } \\
\text { diagnosis }\end{array}$ & $7(9.21)$ & $7(11.67)$ & $0(0)$ & \\
\hline $\begin{array}{l}\text { Facial bone fracture } \pm \text { soft tissue } \\
\text { injury to head }\end{array}$ & $8(10.53)$ & $7(11.67)$ & $1(6.25)$ & \\
\hline $\begin{array}{l}\text { Skull fracture } \pm \text { soft tissue injury } \\
\text { to head }\end{array}$ & $5(6.58)$ & $4(6.67)$ & $1(6.25)$ & \\
\hline Intracranial pathology + other & $13(17.11)$ & $9(15)$ & $4(25)$ & \\
\hline $\begin{array}{l}\text { Intracranial pathology + skull } \\
\text { fracture }\end{array}$ & $3(3.95)$ & $1(1.67)$ & $2(12.5)$ & \\
\hline Brachycephaly status, $n$ (\%) & $37(48.68)$ & $26(43.33)$ & $11(68.75)$ & 0.07 \\
\hline \multicolumn{5}{|l|}{ History-scale, $n(\%)$} \\
\hline No trauma of any kind & $20(26.32)$ & $17(28.33)$ & $3(18.75)$ & \multirow{5}{*}{0.48} \\
\hline Direct physical abuse & $29(38.16)$ & $21(35)$ & $8(50)$ & \\
\hline Neglect-physical & $6(7.89)$ & $4(6.67)$ & $2(12.5)$ & \\
\hline Neglect-supervisory & $14(18.42)$ & $11(18.33)$ & $3(18.75)$ & \\
\hline Direct abuse + neglect (either) & $7(9.21)$ & $7(11.67)$ & $0(0)$ & \\
\hline
\end{tabular}

Abbreviations: IQR, interquartile range; NAT, nonaccidental trauma. 
Table 4 Sample characteristics of NAT patients by plagiocephaly status

\begin{tabular}{|c|c|c|c|c|}
\hline & \multirow[t]{2}{*}{ Overall $(n=38)$} & \multicolumn{2}{|c|}{ Plagiocephaly } & \multirow[t]{2}{*}{$p$-Value } \\
\hline & & No $(n=29)$ & Yes $(n=9)$ & \\
\hline Age, median (IQR) & $9.5(3-24)$ & $12(4-24)$ & $3(1.5-9)$ & 0.23 \\
\hline Median income, median (IQR) & $46,306.5(37,901-57,901)$ & $48,632(36,894-57,901)$ & $43,981(39,639-54,278)$ & 0.83 \\
\hline \multicolumn{5}{|l|}{ Age group, $n(\%)$} \\
\hline$\leq 12$ & $24(63.16)$ & $17(58.62)$ & $7(77.78)$ & \multirow{2}{*}{0.44} \\
\hline$>12$ & $14(36.84)$ & $12(41.38)$ & $2(22.22)$ & \\
\hline \multicolumn{5}{|l|}{ Sex, $n(\%)$} \\
\hline Male & $17(44.74)$ & $14(48.28)$ & $3(33.33)$ & \multirow{2}{*}{0.48} \\
\hline Female & $21(55.26)$ & $15(51.72)$ & $6(66.67)$ & \\
\hline \multicolumn{5}{|l|}{ Ethnicity, n (\%) } \\
\hline Non-Hispanic & $19(50)$ & $15(51.72)$ & $4(44.44)$ & \multirow{2}{*}{$>0.999$} \\
\hline Hispanic & $19(50)$ & $14(48.28)$ & $5(55.56)$ & \\
\hline \multicolumn{5}{|l|}{ Race, $n(\%)$} \\
\hline White & $24(63.16)$ & $18(62.07)$ & $6(66.67)$ & \multirow{3}{*}{0.96} \\
\hline Black & $5(13.16)$ & $4(13.79)$ & $1(11.11)$ & \\
\hline Other & $4(10.53)$ & $3(10.34)$ & $1(11.11)$ & \\
\hline \multicolumn{5}{|l|}{ Initial-pre, n (\%) } \\
\hline No trauma to the head & $9(23.68)$ & $7(24.14)$ & $2(22.22)$ & \multirow{6}{*}{0.30} \\
\hline Soft tissue injury to head & $5(13.16)$ & $4(13.79)$ & $1(11.11)$ & \\
\hline $\begin{array}{l}\text { Facial bone fracture } \pm \text { soft } \\
\text { tissue injury to head }\end{array}$ & $6(15.79)$ & $6(20.69)$ & $0(0)$ & \\
\hline $\begin{array}{l}\text { Skull fracture } \pm \text { soft tissue injury } \\
\text { to head }\end{array}$ & $2(5.26)$ & $2(6.9)$ & $0(0)$ & \\
\hline Intracranial pathology \pm other & $13(34.21)$ & $9(31.03)$ & $4(44.44)$ & \\
\hline $\begin{array}{l}\text { Intracranial pathology + skull } \\
\text { fracture }\end{array}$ & $3(7.89)$ & $1(3.45)$ & $2(22.22)$ & \\
\hline Brachycephaly status, $n$ (\%) & $21(55.26)$ & $14(48.28)$ & $7(77.78)$ & 0.15 \\
\hline \multicolumn{5}{|l|}{ History-scale, $n(\%)$} \\
\hline Direct physical abuse & $28(73.68)$ & $20(68.97)$ & $8(88.89)$ & \multirow{4}{*}{0.25} \\
\hline Neglect-physical & $2(5.26)$ & $1(3.45)$ & $1(11.11)$ & \\
\hline Neglect-supervisory & $1(2.63)$ & $1(3.45)$ & $0(0)$ & \\
\hline Direct abuse + neglect (either) & $7(18.42)$ & $7(24.14)$ & $0(0)$ & \\
\hline
\end{tabular}

Abbreviations: IQR, interquartile range; NAT, nonaccidental trauma.

\section{Discussion}

Our findings demonstrate no correlation between DP and a history of neglect or trauma in our rural, pediatric population. Additionally, none of the demographic variables assessed showed a significant correlation with plagiocephaly, neglect, or trauma. The prevalence of DP for the entire cohort, as well as in the NAT and neglect groups independently, was within the range of DP prevalence nationally-20 to $50 \%{ }^{14,15}$ As of this writing, the concept of DP as an associated risk factor for abuse has not been explored in the literature, so there is little evidence available to help place our findings in context.

Numerous confounders could explain the lack of relationship between DP and NAT/neglect observed in this study. We chose to evaluate children younger than the age of 4 years for maximum coverage, since most of the resulting morbidity and mortality from NAT or neglect have been shown to occur before the age of 3 years. ${ }^{16}$ However, the wide age range could have confounded our findings. To combat this, we stratified the data based on children less than and more than 12 months of age, but significant correlation between NAT/neglect and DP was still not established. Since the median age for the NAT and neglect groups were 3 and 12 months, respectively, adaptation of the skull in the neglect group could have potentially skewed the prevalence rates in this study. Prior work done by Hutchison et $\mathrm{a}^{17}$ demonstrated a drastic decrease in DP prevalence between the first and second years of life, from 6.8 to 3.3\%, respectively, thus indicating the possibility of natural skull correction over time. This decline in plagiocephaly over the first year of life is supported in the systematic review 
Table 5 Sample characteristics of neglect patients by plagiocephaly status

\begin{tabular}{|c|c|c|c|c|}
\hline & \multirow[t]{2}{*}{ Overall $(n=38)$} & \multicolumn{2}{|c|}{ Plagiocephaly } & \multirow[t]{2}{*}{$p$-Value } \\
\hline & & No $(n=31)$ & Yes $(n=7)$ & \\
\hline Age, median (IQR) & $23.5(10-36)$ & $24(10-36)$ & $12(3-24)$ & 0.09 \\
\hline Median income, median (IQR) & $53,396(43,981-63,837)$ & $56,396(43,981-63,837)$ & $50,192(39,639-57,901)$ & 0.29 \\
\hline \multicolumn{5}{|l|}{ Age group, $n(\%)$} \\
\hline$\leq 12$ & $13(34.21)$ & $9(29.03)$ & $4(57.14)$ & \multirow{2}{*}{0.20} \\
\hline$>12$ & $25(65.79)$ & $22(70.97)$ & $3(42.86)$ & \\
\hline \multicolumn{5}{|l|}{ Sex, $n(\%)$} \\
\hline Male & $20(52.63)$ & $14(45.16)$ & $6(85.71)$ & \multirow{2}{*}{0.09} \\
\hline Female & $18(47.37)$ & $17(54.84)$ & $1(14.29)$ & \\
\hline \multicolumn{5}{|l|}{ Ethnicity, $n$ (\%) } \\
\hline Non-Hispanic & $13(40.63)$ & $11(40.74)$ & $2(40)$ & \multirow{2}{*}{$>0.999$} \\
\hline Hispanic & $19(59.38)$ & $16(59.26)$ & $3(60)$ & \\
\hline \multicolumn{5}{|l|}{ Race, $n(\%)$} \\
\hline Not reported & $4(10.53)$ & $4(12.9)$ & $0(0)$ & \multirow{4}{*}{0.54} \\
\hline White & $22(57.89)$ & $16(51.61)$ & $6(85.71)$ & \\
\hline Black & $5(13.16)$ & $5(16.13)$ & $0(0)$ & \\
\hline Other & $7(18.42)$ & $6(19.35)$ & $1(14.29)$ & \\
\hline \multicolumn{5}{|l|}{ Initial pre, $n(\%)$} \\
\hline $\begin{array}{l}\text { Neglect only-no direct physical } \\
\text { trauma of any kind }\end{array}$ & $9(23.68)$ & $7(22.58)$ & $2(28.57)$ & \multirow{6}{*}{0.12} \\
\hline No trauma to the head & $1(2.63)$ & $0(0)$ & $1(14.29)$ & \\
\hline Soft tissue injury to head & $16(42.11)$ & $14(45.16)$ & $2(28.57)$ & \\
\hline $\begin{array}{l}\text { Soft tissue injury + concussion } \\
\text { diagnosis }\end{array}$ & $7(18.42)$ & $7(22.58)$ & $0(0)$ & \\
\hline $\begin{array}{l}\text { Facial bone fracture } \pm \text { soft tissue } \\
\text { injury to head }\end{array}$ & $2(5.26)$ & $1(3.23)$ & $1(14.29)$ & \\
\hline $\begin{array}{l}\text { Skull fracture } \pm \text { soft tissue injury } \\
\text { to head }\end{array}$ & $3(7.89)$ & $2(6.45)$ & $1(14.29)$ & \\
\hline Brachycephaly status, n (\%) & $16(42.11)$ & $12(38.71)$ & $4(57.14)$ & 0.43 \\
\hline \multicolumn{5}{|l|}{ History-scale, $n$ (\%) } \\
\hline No trauma of any kind & $20(52.63)$ & $17(54.84)$ & $3(42.86)$ & \multirow{4}{*}{0.77} \\
\hline Direct physical abuse & $1(2.63)$ & $1(3.23)$ & $0(0)$ & \\
\hline Neglect-physical & $4(10.53)$ & $3(9.68)$ & $1(14.29)$ & \\
\hline Neglect-supervisory & $13(34.21)$ & $10(32.26)$ & $3(42.86)$ & \\
\hline
\end{tabular}

Abbreviations: IQR, interquartile range.

by Bialocerkowski et al, which showed DP rates peaking at 6 to 7 months and declining until 2 years of age. ${ }^{14}$

There is currently no research that quantifies the degree of correction in the first year of children's lives. Prevalence has been shown to peak at $22.1 \%$ within the first 6 months of life, ${ }^{14}$ and incidence rates for children between 7 and 12 weeks old have been reported as high as $46.6 \% .^{18}$ These studies help illustrate the absence of agreement on the true prevalence or incidence of DP over the age range represented in our study. Establishing true prevalence of the condition is made even more complicated by the fact that DP in infants can vary depending on the clinician's judgment as DP is not a standardized diagnosis and is generally left to the experience of the treating clinician. A lack of standardization is also reflected in our NAT and neglect cohorts, as diagnosis of abuse is often difficult and subjective. Our reliance on physician's reports in the electronic medical record (EMR) to classify subjects, even if those diagnoses were made by a child abuse specialist, were susceptible to subjective variance.

Our technique for evaluating DP also could have contributed to the negative findings. Our method of assessing plagiocephaly involved calculating CVAI through the utilization of axial CT scans, and this process, while convenient for our study, has the potential to introduce some systematic error. In the literature, common methods of assessing DP include the Argenta scale ${ }^{19}$, optical three-dimensional imaging, ${ }^{20,21}$ anthropometric measurements using calipers ${ }^{21}$ 
plagiocephalometry, ${ }^{22,23}$ and the flexicurve. ${ }^{24}$ Among these various methods of plagiocephaly assessment, the CVAI has been shown to be a reliable method of evaluation, with prior studies affirming the use of visual assessments, flexicurve, and anthropometric measurements with calipers. ${ }^{13,22,24}$ That said, anthropometric measurements can involve the creation of outlines for head circumference, ${ }^{24}$ and we justified the use of CT scans as substitutes for these circumferential outlines. In choosing to apply the CVAI to CT scans, we assumed the results would be applicable to CVAI measurements via the different means listed earlier, particularly when CT scans are ordered for suspected abuse/head trauma. Also, it is important to note that the CVAI is not a perfect measurement of plagiocephaly even with in-person measurement, as detection of DP may fail to account for more complex malformations of the skull. Newer techniques have been proposed to accurately diagnose DP that involves mathematical models for assessing the entire calvarium. ${ }^{7}$

In addition to the above, our study was limited by sample size. Negative findings require significant power, and with a total of 76 subjects, we posit that a larger study would be necessary to confirm the lack of relationship between our studied variables. Our choice of methodology was partly responsible for the small sample size, as 320 of the 396 charts that met our inclusion criteria did not have available CT scans for evaluation. Future studies will likely require a prospective approach, as plagiocephaly is not often evaluated objectively in clinical settings, and the results of such evaluations are, in the authors' experience, not formally recorded in the EMR. It is unusual that we found no demographic associations to neglect or NAT because factors such as age and SES have been correlated to rate and type of abuse in the literature. ${ }^{25,26}$ This absence of correlation likely stems from the aforementioned sample size as well as the fact that the median income for our families was between $\$ 46,000$ and $\$ 50,000$, well below the national average $(\$ 61,372$ in 2017). Thus, we could not confirm the SES association with DP because our entire cohort was below the national average, so a stratification could not be created to appreciate the relationship between SES and DP in this study (-Tables 4 and $\mathbf{5}$ ). Furthermore, our evaluation of SES was accomplished using U.S. census data on the median household income for the subject's listed zip code of residence. This represents a relatively crude method of evaluating SES, and this type of categorization could have decreased the sensitivity of our methods.

\section{Conclusion}

In conclusion, the prevalence of DP within the NAT and neglect group was 23.7 and $18.4 \%$, respectively, and the total prevalence within the combined NAT and neglect cohort was $21 \%$. These percentages are consistent with the general rates of DP reported in the literature. DP did not prove to be predictive of either NAT or neglect. Future work will likely require a prospective approach, larger sample size, and a local control group to validate our findings. We hope the results of this work help guide future efforts to characterize trauma and plagiocephaly in the pediatric population.

\section{Note}

This study is approved by the Institutional Review Board.

\section{Conflict of Interest}

None declared.

\section{Acknowledgment}

The authors would like to acknowledge the Texas Tech University Health Sciences Center Clinical Research Institute.

\section{References}

1 Paul AR, Adamo MA. Non-accidental trauma in pediatric patients: a review of epidemiology, pathophysiology, diagnosis and treatment. Transl Pediatr 2014;3(3):195-207

2 Vinchon M, Defoort-Dhellemmes S, Desurmont M, Dhellemmes P. Accidental and nonaccidental head injuries in infants: a prospective study. J Neurosurg 2005;102(4, Suppl):380-384

3 Reece RM, Sege R. Childhood head injuries: accidental or inflicted? Arch Pediatr Adolesc Med 2000;154(1):11-15

4 Marek AP, Nygaard RM, Cohen EM, et al. Rural versus urban pediatric non-accidental trauma: different patients, similar outcomes. BMC Res Notes 2018;11(1):519

5 Walsh WA, Mattingly MJ, Understanding child abuse in rural and urban America: risk factors and maltreatment substantiation; 2012 The Carsey School of Public Policy at the Scholars' Repository: 170

6 United States Center for Disease Control (CDC) [Internet]. Risk and Protective Factors | Child Abuse and Neglect | Violence Prevention | Injury Center | CDC. Available at: https://www.cdc.gov/violenceprevention/childabuseandneglect/riskprotectivefactors.html. Accessed April 22, 2019

7 Palermo T, Pereira A, Neijhoft N, et al. Risk factors for childhood violence and polyvictimization: a cross-country analysis from three regions. Child Abuse Negl 2019;88:348-361

8 Schols MWA, Serie CMB, Broers NJ, de Ruiter C. Factor analysis and predictive validity of the Early Risks of Physical Abuse and Neglect Scale (ERPANS): a prospective study in Dutch public youth healthcare. Child Abuse Negl 2019;88:71-83

9 Bailhache M, Leroy V, Pillet P, Salmi LR. Is early detection of abused children possible?: a systematic review of the diagnostic accuracy of the identification of abused children. BMC Pediatr 2013;13:202

10 Martiniuk AL, Vujovich-Dunn C, Park M. Yu W, Lucas BR. Plagiocephaly and developmental delay: a systematic review.J Dev Behav Pediatr 2017;38(1):67-78

11 Loveday BP, de Chalain TB. Active counterpositioning or orthotic device to treat positional plagiocephaly? J Craniofac Surg 2001;12(4):308-313

12 Holowka MA, Reisner A, Giavedoni B, Lombardo JR, Coulter C. Plagiocephaly severity scale to aid in clinical treatment recommendations. J Craniofac Surg 2017;28(3):717-722

13 Vanderminden J, Hamby S, David-Ferdon C, et al. Rates of neglect in a national sample: child and family characteristics and psychological impact. Child Abuse Negl 2019;88:256-265

14 Bialocerkowski AE, Vladusic SL, Wei Ng C. Prevalence, risk factors, and natural history of positional plagiocephaly: a systematic review. Dev Med Child Neurol 2008;50(8):577-586

15 Ditthakasem K, Kolar JC. Deformational plagiocephaly: a review. Pediatr Nurs 2017;43(2):59-64

16 Mawji A, Vollman AR, Fung T, Hatfield J, McNeil DA, Sauvé R. Risk factors for positional plagiocephaly and appropriate time 
frames for prevention messaging. Paediatr Child Health 2014;19(8):423-427

17 Hutchison BL, Hutchison LA, Thompson JM, Mitchell EA. Plagiocephaly and brachycephaly in the first two years of life: a prospective cohort study. Pediatrics 2004;114(4):970-980

18 Spermon J, Spermon-Marijnen R, Scholten-Peeters W. Clinical classification of deformational plagiocephaly according to Argenta: a reliability study.J Craniofac Surg 2008;19(3):664-668

19 Spitzer MJ, Kramer M, Neukam FW, Nkenke E. Validation of optical three-dimensional plagiocephalometry by computed tomography, direct measurement, and indirect measurements using thermoplastic bands. J Craniofac Surg 2011;22(1):129-134

20 McKay DR, Davidge KM, Williams SK, et al. Measuring cranial vault volume with three-dimensional photography: a method of measurement comparable to the gold standard. J Craniofac Surg 2010;21(5):1419-1422

21 Glasgow TS, Siddiqi F, Hoff C, Young PC. Deformational plagiocephaly: development of an objective measure and determination of its prevalence in primary care. J Craniofac Surg 2007;18(1):85-92
22 van Vlimmeren LA, Takken T, van Adrichem LN, van der Graaf Y, Helders PJ, Engelbert RH. Plagiocephalometry: a non-invasive method to quantify asymmetry of the skull; a reliability study. Eur J Pediatr 2006;165(3):149-157

23 Leung A, Watter P, Gavranich J. A clinical tool to measure plagiocephaly in infants using a flexicurve: a reliability study. Pediatric Health Med Ther 2013;4:109-115

24 Jelinek HF, Strachan B, O'Connor B, Khandoker A. A continuous point measure for quantifying skull deformation in medical diagnostics. Healthc Technol Lett 2014;1(2):56-58

25 Siegenthaler $\mathrm{MH}$. Methods to diagnose, classify, and monitor infantile deformational plagiocephaly and brachycephaly: a narrative review. J Chiropr Med 2015;14(3):191-204

26 Kim PT, McCagg J, Dundon A. Ziesler Z, Moody S, Falcone RA Jr. Consistent screening of admitted infants with head injuries reveals high rate of nonaccidental trauma. J Pediatr Surg 2017;52(11):1827-1830 